\title{
Alexandre Dumas, Les Deux Révolutions. Paris (1789) et Naples (1799)
}

\section{Lise Sabourin}

\section{Q OpenEdition}

1 Journals

\section{Édition électronique}

URL : http://journals.openedition.org/studifrancesi/2206

DOI : 10.4000/studifrancesi.2206

ISSN : 2421-5856

Éditeur

Rosenberg \& Sellier

\section{Édition imprimée}

Date de publication : 1 avril 2014

Pagination : 164

ISSN : 0039-2944

\section{Référence électronique}

Lise Sabourin, «Alexandre Dumas, Les Deux Révolutions. Paris (1789) et Naples (1799)», Studi Francesi [En ligne], 172 (LVIII | I) | 2014, mis en ligne le 01 avril 2014, consulté le 18 septembre 2020. URL : http://journals.openedition.org/studifrancesi/2206 ; DOI : https://doi.org/10.4000/studifrancesi.2206

Ce document a été généré automatiquement le 18 septembre 2020.

\section{(c) $(1) \&$}

Studi Francesi è distribuita con Licenza Creative Commons Attribuzione - Non commerciale - Non opere derivate 4.0 Internazionale. 


\title{
Alexandre Dumas, Les Deux Révolutions. Paris (1789) et Naples (1799)
}

\author{
Lise Sabourin
}

\section{RÉFÉRENCE}

ALEXANDRE DUMAS, Les Deux Révolutions. Paris (1789) et Naples (1799), traduit de l'italien et annoté par Jean-Paul DESPRAT et Philippe GODOY, préfacé par Claude sCHOPP, Paris, Fayard, 2012, pp. 1003.

1 Faute du manuscrit français de Dumas, actuellement non localisé, peut-être détruit, Jean-Paul Desprat et Philippe Godoy nous fournissent leur traduction de la Storia dei Borboni di Napoli parue dans «L'Indipendente» de mai 1862 à 1864, puisque sa publication française n'a été assurée que partiellement vu la faillite du «Monte-Cristo» où elle avait commencé parallèlement en juillet 1862. Cet ouvrage a donc l'avantage de rassembler ces livraisons pour le lectorat français comme l'a fait Luogo dans l'unique édition existant en italien (Napoli, Marotta e Marotta, 2002). Or cet écrit intéresse les deux nations puisqu'il veut faire la comparaison entre Louis XVI durant la Révolution de 1789 et Ferdinand IV face aux soubresauts de la République parthénopéenne de 1799.

2 On sait combien Alexandre Dumas est concerné par l'épopée révolutionnaire de Championnet à Naples puisque son père, le général Dumas, croyant débarquer en territoire républicain à son retour d'Égypte, se retrouva prisonnier du Bourbon qui devait prendre le titre de Ferdinand ${ }^{\text {er }}$ quand il devint roi des Deux-Siciles en 1815. L'orphelin appauvri du général d'Empire entretient donc une relation très particulière avec la capitale de la Campanie, pris entre sa rancœur filiale envers la redoutable Marie-Caroline, sœur vengeresse de Marie-Antoinette, et sa propre fascination pour Naples et ses habitants, découverts avec passion lors de son séjour de 1835 au retour de 
son voyage en Méditerranée. Il est de plus, quand il entreprend cette histoire, devenu le directeur du Musée national et des fouilles archéologiques en remerciement de son action au service de Garibaldi, notamment comme fournisseur des armes qui ont permis de soutenir l'expédition des Mille.

3 La démarche est compréhensible puisque le fondateur-directeur de «L'Indipendente» écrit la majeure partie des 750 numéros de son quotidien, auxquels donc va s'adjoindre en supplément cette Histoire des Bourbons de Naples, mais elle est aussi difficile, car existent déjà à l'époque plusieurs récits historiques dus à Cuoco, Botta et Colletta, ainsi que l'indique d'emblée Dumas dans son introduction (p. 37-45). Il justifie donc son entreprise par la mise à disposition grâce à son ami Garibaldi des archives et correspondances secrètes des Bourbons conservées malgré le décret de Ferdinand ordonnant en 1800 de les brûler.

4 L'ouvrage, préfacé par Claude Schopp (pp. 9-36), est découpé en quatre parties: depuis l'installation de l'espagnol Charles III en Italie en 1733 jusqu'aux démêlés de Ferdinand IV entre le Pape et Hamilton (pp. 49-275), les conséquences de la Révolution française sur le royaume de Naples, avec la fuite des Bourbons devant l'invasion conduite par Championnet (pp. 279-533), l'installation de la République parthénopéenne et le contrecoup opéré sous l'impulsion de Marie-Caroline (pp. 537-779), enfin les aléas des sanfédistes, les destinées de Ruffo et Caracciolo, jusqu'au retour des Français à Marengo et la fin étonnante de Nelson et Lady Hamilton (pp. 783-1000).

5 Tout l'intérêt de la version dumasienne des faits, souvent marquée de simplification, réduisant un peu l'histoire à des conflits personnels d'intérêts, réside dans la verve et l'alacrité avec lesquelles le romancier de La San Felice et des Mémoires d'une favorite comme de Joseph Balsamo et de La Comtesse de Charny narre les anecdotes qu'il a dégagées du matériau exceptionnel de documents dont il dispose. Dumas, qui a vécu paradoxalement dans la proximité du duc d'Orléans, règle certes ses comptes avec les Bourbons, en digne héritier républicain de ce «Monsieur l'Humanité» qu'était son père face au Premier Consul, mais il a aussi l'ambition d'insuffler au peuple napolitain la fierté de sa propre histoire, parallèlement à sa mission de mise en valeur archéologique et pittoresque de la région. 